\title{
Minimal Access Surgery - the Mile Stones
}

\author{
Fazl Q Parray, M.S., Suhail Farooq Mir, M.B, Sameer Hassan Naqash, M.S., Khursheed Alam Wani, M.S. \\ Department of General and Minimal Access Surgery, Sher-i-Kashmir Institute of Medical Sciences, Soura Srinagar, Kashmir
}

\section{A B S T R A C T}

\begin{abstract}
Surgery has come a long way from the crude methods of the past to the refined techniques of the present. Improvements in techniques and tools have made minimal-access procedures increasingly available. Growing popularity of laparoscopy has resulted in greater numbers of patients available for outcomes analysis. In future remote handling technology will overcome the manipulative restriction in the current instruments. Robotic arms with multiple degrees of freedom let a surgeon achieve a degree of dexterity which is amiss in rigid laparoscopic instruments. The future is knocking on the door and banging hard, but, as with all forms of technology, it depends upon how good the training is, and how much the learning curve can be shortended. JMS 2012;15(2):91-100.
\end{abstract}

Key words: Minimal Access Surgery, laparoscopy, robotic arms

Surgery just like every other field of medicine has evolved dramatically over a period of time. With the use of inhalation anesthetics at Massachusetts General Hospital in 1846, the field of surgery truly expanded. Before then, surgical procedures were avoided and, if performed, were completed as quickly as possible. The fastest surgeon would be regarded as the best surgeon, who thereby caused less pain to his restrained and un-anesthetized patient. ${ }^{1}$ As times passed refinement in surgical techniques and upgradation of surgical skills followed suit.

A giant leap in the field of surgery was development of techniques of minimal access. Initially, larger surgical incisions and adequate exposure was mandatory for a successful operation. Exposure is still essential for a safe and successful operation, except that, large incisions on the abdomen over time, have given way to 3 or 4 small buttonhole incisions, with better visualization of anatomy and the results being as good as or better than open surgery.

\footnotetext{
Correspondence:

Dr. Fazl Q Parray

44-Rawal Pora, Government Housing Colony (Sanat Nagar)

Srinagar-190005, J\&K, India

E-mail:fazlparray@rediffmail.com
}

The earliest recorded references to endoscopy date to ancient times of Hippocrates. In his description there is explanation of rectum examination with a speculum. This was probably the first attempt at minimal access. The second half of the 20th century saw exponential growth in the field of minimal access surgery and as of today, most abdominal surgeries are performed by using minimal access. The advancements in laparoscopy paralleled the advancement of skills required for the same, better understanding of ergonomics and advancement in optics.

\section{Evolution of laparoscopy}

Laparoscopy started from humble beginnings and advanced gradually but steadily to the modern day endo-suite theatres, hi definition cameras and fast micro-processors.

Aranzi in 1585 was the first to use a light source for an endoscopic procedure, focusing sunlight through a flask of water and projecting the light into the nasal cavity.

The term "trocar," was coined in 1706, and is derived from trois (three), carré (square) i.e., 'three-edged'; it is a three-faced instrument consisting of a perforator enclosed in a metal cannula. 
In 1853, Antoine Jean Desormeaux, a French surgeon, first introduced the 'Lichtleiter", which had previously been invented by Bozzini, to a patient. For many surgeons he is considered as the "Father of Endoscopy". A "Lichtleiter" consisted of an aluminum tube, illuminated by a wax candle, with fitted mirrors to reflect images.

Kussmaul performed the first esophago-gastroscopy in 1868, on a professional sword swallower, thus helping initiate efforts at instrumentation of the gastrointestinal tract. ${ }^{2}$

The first experimental laparoscopy was performed in Berlin in 1901 by German surgeon Georg Kelling, who used a cystoscope to peer into the abdomen of a dog. ${ }^{3}$

In 1920, Zollikofer of Switzerland discovered the benefit of $\mathrm{CO}_{2}$ gas to use for insufflation, rather than filtered atmospheric air or nitrogen.

In 1934, John C. Ruddock, an American surgeon described laparoscopy as a good diagnostic method and he termed it to be many times superior to laparotomy.

In 1938, Janos Veress of Hungary developed a specially designed spring-loaded needle. Veress needle as of today is used to create pneumoperitoneum.

In 1953, the rigid rod lens system was discovered by Professor Hopkins.

In 1960, Kurt Semm, a German gynecologist invented the automatic insufflator.

In 1970's, Gynecologists had thoroughly incorporated the technique into their practice. However, general surgeons were still reluctant to embrace laparoscopy.

In 1977, Kurt Semm first time demonstrated endo-loop suturing technique in laparoscopic surgery.

In 1978, Hasson introduced an alternative method of trocar placement. He proposed a blunt mini-laparotomy which permits direct visualization of trocar entrance into the peritoneal cavity.

In 1983, Semm, a German gynecologist, performed the first laparoscopic appendectomy.

The first documented laparoscopic cholecystectomy was performed by Erich Mühe in Germany in 1985.

In 1987, Ger reported first laparoscopic repair of inguinal hernia using prototype stapler.

In 1987, Phillipe Mouret was credited with performing the first laparoscopic cholecystectomy in Lyons, France using video technique.

In 1989, Reddick and Olsen reported that CBD injury after laparoscopic cholecystectomy is 5 times that with conventional cholecystectomy.

In 1990, Bailey and Zucker in USA popularized laparoscopic anterior highly selective vagotomy combined with posterior truncal vagotomy.

In 1994, A robotic arm was designed to hold the telescope with the goal of improving safety and reducing the need of skilled camera operator.

\section{The Laparoscopist's armamentarium}

The trolley has a drawer and three shelves. The upper shelves support the video monitor unit. Recently ceiling mounted trolleys have been launched which are ergonomically better, consume less space and have no cables running across the floor of the operation theatre.

Equipment is broadly divided into 2 categories:

1) Electronic Equipment

2) Hand Equipment

\section{Electronic Equipment}

1. Endo-vision Camera

2. Video Monitor

3. Telescope

4. Fibro Optic Light Cable

5. Light Source

6. $\mathrm{CO}_{2}$ Insufflator

7. Suction/Irrigation

8. Energy Source

\section{Hand Instruments}

1. Veress Needle

2. Trocars And Cannulas

3. Dissector

4. Traumatic \& Atraumatic Graspers

5. Scissors

6. Sutures/Clips/Staples

7. Retrieval Bags

\section{Light cable and light source}

Minimal access surgery (MAS) depends on the artificial light to illuminate organs in closed body cavities. In the beginning mirrors were used to reflect the light onto the area of interest, where the direct light access was not possible.

Bruck, a Dentist from Breslau, in 1867, made a platinum wire loop which he heated with electric current, and used that as a light source for purpose of surgery.

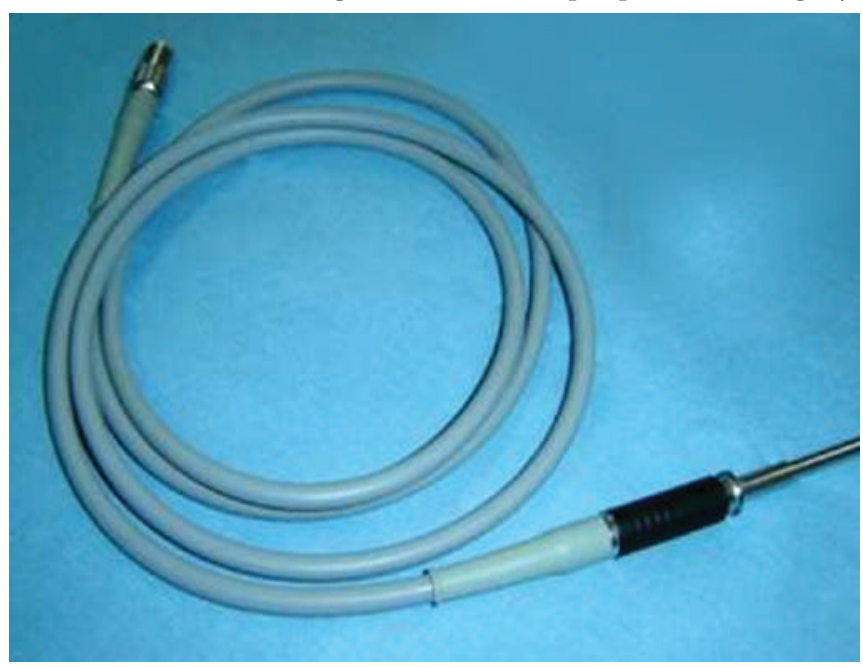

FIGURE 1: A typical fiber optic cable 


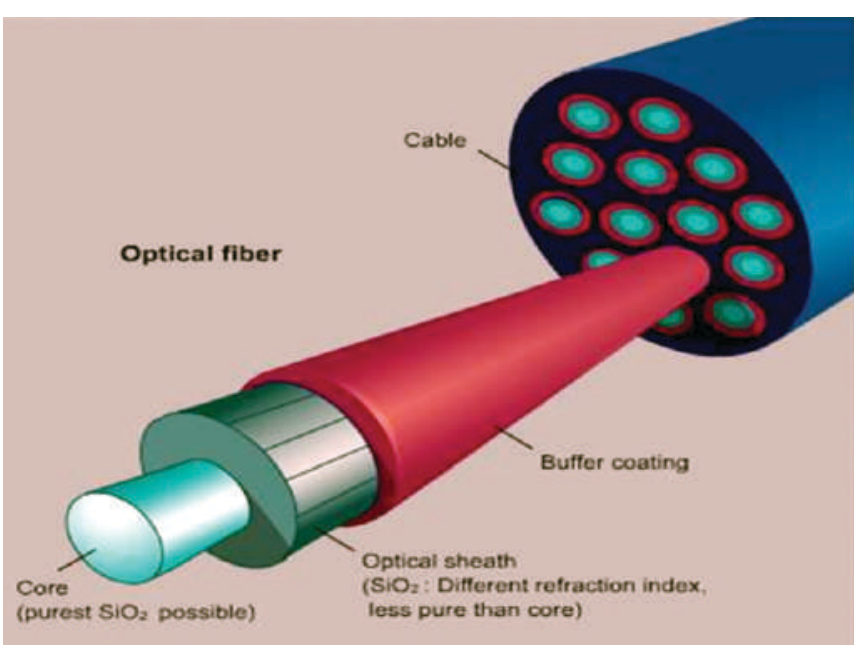

FIGURE 2: Cross-section of a fiber optic cable

Endoscopy was performed, by using tungsten light bulbs inside the body cavity before 1954. These bulbs were emitting low frequency red color of light.

In 1954 a major milestone took place in the form of development of fiber optic cables. Based on the principle of total internal reflection of light, using fiber optic cables, light could be conducted along a curved glass rod due to multiple total internal reflections at the walls of the rod. There would be no loss in the intensity of light entering at one end of the cable and leaving at the other end, due to the phenomenon of total internal reflection.

Nowadays there are two types of light cable available in market.

1. Fiber Optic cable

2. Liquid crystal Gel cable

Fiber optic cables are made up of a bundle of optical fiber glass thread swaged at both ends, with the fiber size varying between 10 to $25 \mathrm{~mm}$ in diameter. They have a very high quality of optical transmission, but are fragile.

Some optical fibers break on constant usage. The loss of optical fibers may be seen, when one end of the cable is viewed in daylight, in the form of black spots.

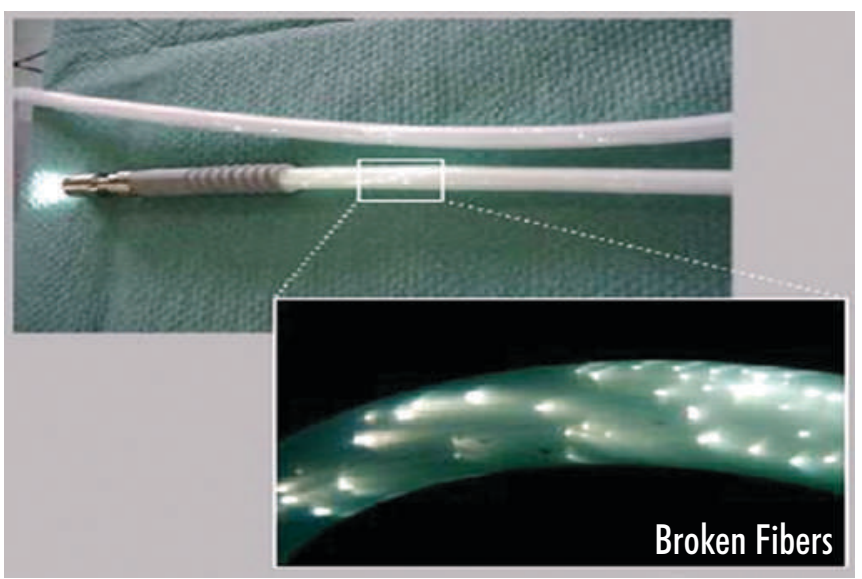

FIGURE 3: Broken fibers in fiber optic cable
Liquid crystal Gel cables are made up of a sheath that is filled with a clear optical gel. They transmit light and color better than fiber-optic cables. They are recommended when documentation (movie, photography or TV) is performed.

However, there are disadvantages with these liquid crystal cables. They get heated up more than fiber optic cables and are extremely fragile at the ends. They are also encased in a rigid metal sheath, which makes storage difficult.

A typical light source consist of

i. Alamp

ii. A heat filter

iii. A condensing lens and

iv. Manual or automatic intensity control circuit.

Lamp or bulb is the most important part of the light source. Several modern types of light sources are currently available on the market, which mainly differ on the type of bulb used. Four types of lamps used are:

1. Quartz halogen.

2. Incandescent bulbs.

3. Xenon and

4. Metal halide vapor arc lamp.

Halogen bulbs provide a highly efficient, almost crisp white light source with excellent color rendering. Their electrodes are made of tungsten. The reason for incorporating tungsten as the electrode is that it is the only metal with a sufficiently high melting temperature and sufficient vapor pressure at elevated temperatures. Halogen bulbs are low voltage and have an average life of 2,000 hours. Color temperature of Halogen lamp is $(5000-5600 \mathrm{~K})$. These lamps are cheap and can be used for laparoscopic surgery if low budget setup is required.

Xenon lamps consist of a spherical or ellipsoidal envelope made of quartz glass, which can withstand high thermal loads and high internal pressure. The color temperature of Xenon lamp is 6000-6400 K.

The smaller, pointed electrode is called the cathode, which supplies the current to the lamp and facilitates the emission of electrons, which is collected by the anode, the larger electrode, receives electrons emitted by the cathode. Once the electrons penetrate the anode face, the resulting energy is converted to heat, most of which radiates away.

In metal halide lamp the mix of compounds (comprising mostly salts of rare earths and halides as well as the Mercury which provides the conduction path) is carefully chosen to produce an output which approximates to 'white' light as perceived by the human eye. The two types of metal halide lamps generally used are iron-iodide lamps and gallium-iodide lamps.

The intensity of the light delivered by any lamp also depends on the power supply of the source. However, increasing the power poses a real problem as concerns the heat created. At present, the improvements made to the cameras means that it is possible to return to reasonable 
power levels, of the order of 250 Watts. $400 \mathrm{~W}$ units are, however, preferable in order to guarantee sufficient illumination of the abdomen even when bleeding causes strong light absorption.

The newer light source of Xenon used is defined as a cool light but it is not completely heat free. It also carries a risk of ignition hazard.

Approximately $2 \%$ of energy from a light source is converted to light and remaining $98 \%$ is dissipated as heat. Heat is mainly due to the infrared spectrum of light and due to obstruction in the pathway of light. A heat filter is introduced to filter this infrared light to travel in fiber optic cable.

The purpose of condensing lens is to converge the light emitted by lamp to the area of light cable input. It also increases the light intensity per square $\mathrm{cm}$ of area.

The surgeon can adjust the power level and intensity of light as required. When video cameras are used, close-up viewing is hampered when there is too much light, whereas more distant views may be too dark.

\section{Telescope}

HOPKINS rod-lens telescopes consist of an eyepiece lens, a connection for fiber optic light cables and a jacket tube made of a non-corrosive material, which encloses the rodlens system and a built-in fiber optic light carrier.

\section{Insufflator}

Pneumoperitoneum is required in most of the cases for successful laparoscopy. Pneumoperitoneum is created using an insufflator. The jury has been out in terms of which medium is best for creation of pneumoperitoneum. Most surgeons prefer carbon dioxide gas because it is easily absorbed, and, thus, the risk of embolism is reduced compared with other gases, and also suppresses combustion.

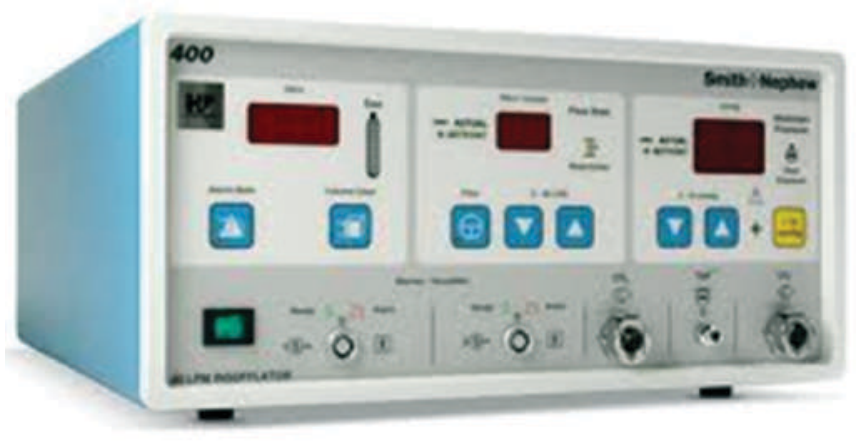

FIGURE 4: Insufflator

After the peritoneum is accessed, the abdomen is insufflated with carbon dioxide gas. The pressure limit usually does not exceed $15 \mathrm{~mm} \mathrm{Hg}$ in adults. It varies in infants and children, and care must be taken to start low (e.g. $1 \mathrm{~L} / \mathrm{min}$ and pressures of $8-12 \mathrm{~mm} \mathrm{Hg}$ ).

\section{Suction irrigation system}

It helps deliver irrigation fluid and aspirate fluids and smoke. It also aids dissection.

\section{Veress Needle}

It is a double barreled device, which has a spring loaded; blunt tipped inner stylet with $2.1 \mathrm{~mm}$ diameter (14G). Standard needle is $80 \mathrm{~mm}$ long. It can insufflate upto $2.5 \mathrm{~L} /$ min and has to be checked before use.

\section{Trocars}

Trocars are surgical instruments used to create ports into the abdomen during laparoscopic surgery. The trocar tip pierces through the abdominal wall to gain access to the peritoneal cavity. After the cannula is stabilized, the abdomen is insufflated with carbon dioxide. The insufflation moves the abdominal wall away from the internal organs to create a working space for the surgeon so other trocars may be thrust manually through the abdominal wall.

\section{Instruments}
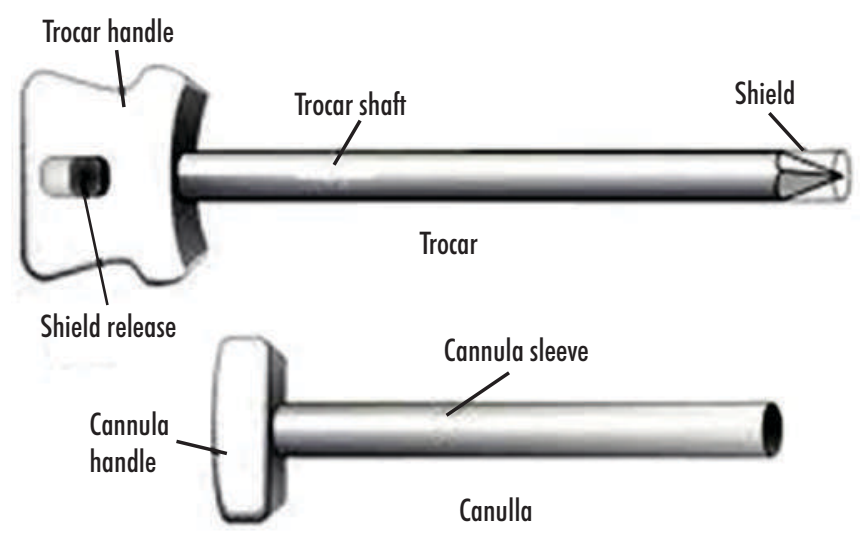

FIGURE 5: Parts of a trocar and its cannula

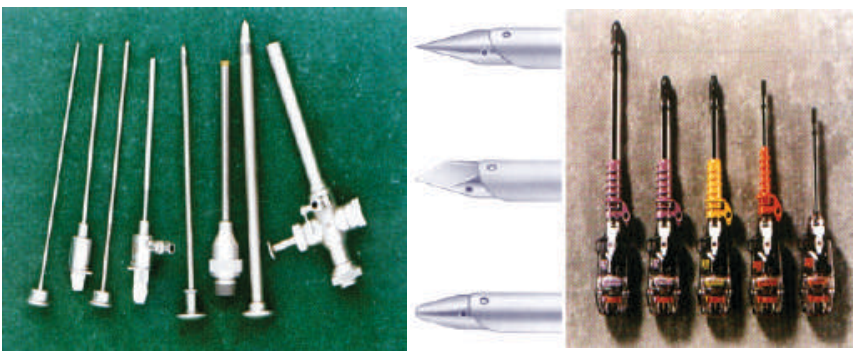

FIGURE 6: Trocars of different sizes

Laparoscopic instruments are designed with long and narrow shafts with the idea that they can negotiate the small sized trocars and can access deeper recesses. Instruments are similar in design and vary only in the structure of their tips. The commonly used ones are:

1. Dissectors (known as Maryland's dissectors).

2. Hooks

3. Spatulas

4. Scissors (both Metzenbaum and Mayo's scissors)

Endoscopic Hand Instruments

A typical endoscopic hand instrument has 3 detachable parts: 


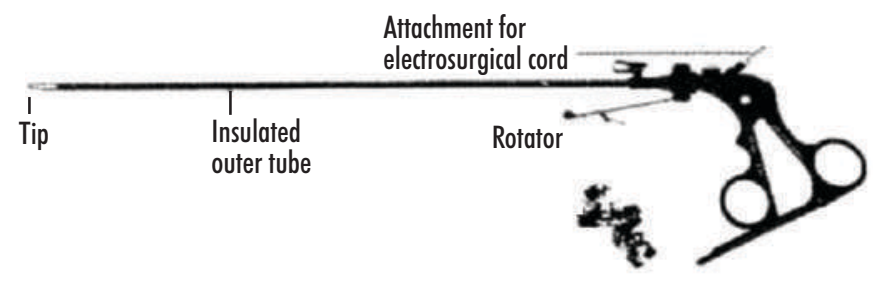

FIGURE 7: A typical hand instrument. Instruments differ only in the insert i.e tip

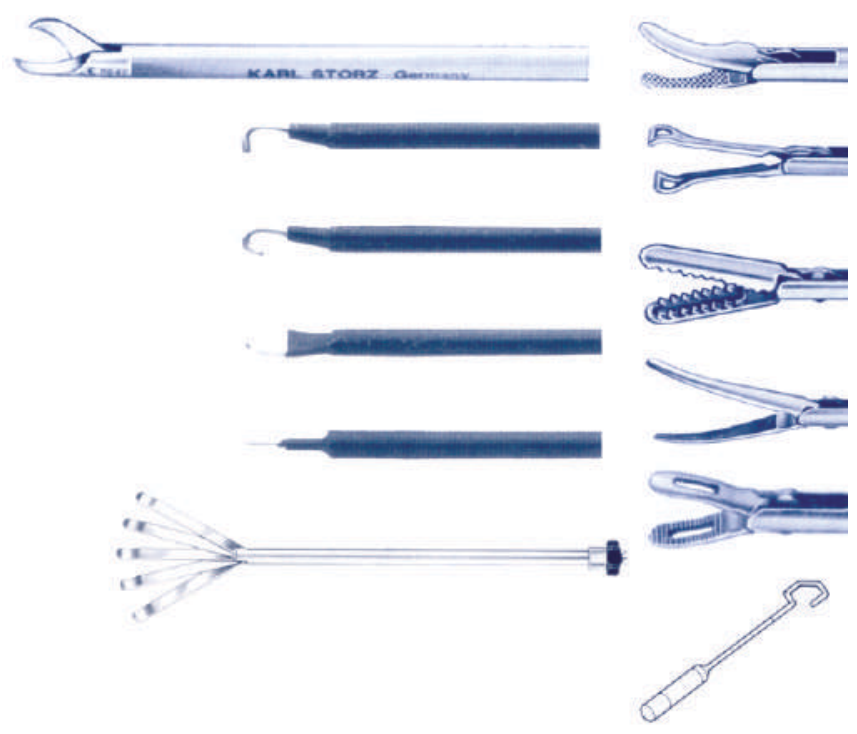

FIGURE 8: Different types of tips of hand instruments

* Handle

$\star \quad$ Insulated outer tube

$\star \quad$ Insert which makes the tip of the instrument

\section{Traumatic and atraumatic forceps}

They have two jaws with rounded edge sand are meant for grasping and precise dissection. They can be used with monopolar/ bipolar coagulation. They have got ratchet locks for maintaining grip.

\section{Suturing / knotting / stapling instruments}

These instruments deliver sutures / clips to secure, hold, join or combine tissues. They include needle holders, clip appliers, staplers, endoscopic linear cutters, endo loops and port closure needles. Clip appliers may be multi load or single load Staplers decrease operative time by achieving rapid tissue approximation and division.

\section{Advantages}

MAS often offer better visualization than open surgery.

- Patients stay in the hospital for a shorter period and recover faster.

- Postoperative pain is reduced, which decreases the need for postoperative analgesics and their complications. Decreased postoperative pain also results in decreased occurrence of basal atelectasis and other pulmonary complications.
- Smaller wounds are associated with fewer wound complications, less scarring, and better cosmesis.

- MAS results in reduction of formation of postoperative adhesions.

- Patients are able to return to their normal activities faster.

- Video imaging allows surgical assistants, anesthesiologists, and nurses to view what the surgeon is doing and to actively participate in the procedure in their respective roles. ${ }^{4}$

- MAS offer dramatic advantages in terms of the quality of life after the operation.

\section{Disadvantages}

- Initial investment cost is significant with laparoscopy because new equipment and training are necessary, and these are available at a substantial price.

- Learning curve for laparoscopy is long and operating time is longer and the complication rate is higher during the learning phase.

- Loss of tactile feedback is the major disadvantage of minimal access surgery. There are efforts to overcome this using Intraoperative ultrasonography.

- With current technology, the video camera can provide only a 2-dimensional image. So the surgeon has to operate in a 3-D space with a 2-D vision.

- Controlling bleeding laparoscopically is technically demanding.

- The instruments are rigid and the angulations at which they can be used are limited.

\section{Surgeries commonly performed using minimal access approach}

It will depend on the Surgeons skill, facilities available and the volume of the centre. Most of the well known centers will go for:

- Diagnostic laparoscopy

- Laparoscopic cholecystectomy

- Laparoscopic appendectomy

- Laparoscopic hernia repair

- Laparoscopic Nissen fundoplication

- Laparoscopic Heller's myotomy ${ }^{32,5}$

- Laparoscopic adrenalectomy

- Laparoscopic splenectomy

- Laparoscopic rectopexy ${ }^{33,6}$

- Laparoscopic nephrectomy

- Laparoscopic colectomy

- Parathyroidectomy (guided with hand held gamma probe)

- Laparoscopic repair of duodenal perforation ${ }^{34,7}$

- Sentinel node biopsy

- Laparoscopic Hepatic resection

- Laparoscopic Gastrectomy 


\section{Complications}

\section{Technique-related complications}

- Complications can be related to placement of the initial trocar or creation of pneumoperitoneum. Underlying vessels or viscera can be injured. These injuries can be minimized by the use of open technique for the first trocar placement. ${ }^{4,8}$

- Complications can also arise from dissection during the procedure. These include direct injuries to hollow and solid organs, as well as thermal injury. These can be minimized by meticulous dissection.

\section{Carbon dioxide-related complications}

- $\quad$ Carbon dioxide can be absorbed through the peritoneal surface, leading to hypercapnia and subsequent acidosis.

- Insufflation of carbon dioxide can also cause cardiovascular compromise because of the "venous tourniquet" like effect. Blood flow from the lower limbs and abdomen is decreased while the arterial perfusion is intact.

- Another serious, but fortunately rare, side complication is gas embolism. This is however minimal with carbon dioxide.

- $\quad$ These complications can be minimized by low pressure and warm humidified gas insufflation, slight hyperventilation, proper fluid resuscitation, and careful monitoring in the operating room.

\section{MAS Applications in the Foregut}

\section{Esophagus}

- Minimal access surgery (MAS) offers a very good alternative to the significant morbidity directly related to the thoracotomy or laparotomy.

- Thoracoscopic repair of esophageal atresia and tracheoesophageal fistula has been reported by Rothenberg in 1999.'

- Heller's myotomy with Dor anterior fundoplication via a laparoscopic approach is an ideal procedure for patients with achalasia. An anterior myotomy is performed $4 \mathrm{~cm}$ above the gastroesophageal junction and extends onto the stomach for $2 \mathrm{~cm}$. A Dor fundoplication is performed, suturing anterior fundic patch to both edges of the myotomized extramucosal incision.

\section{Laparoscopic Insertion of Gastrostomy tube}

- $\quad$ Enteral access with a gastrostomy feeding tube can be achieved by MAS.

- A mini-laparoscope $(1.6 \mathrm{~mm})$ with a single 5-mm trocar at the exit site for the gastrostomy button is used, and no special instrumentation or kits are needed. The operative time ranges from 15-30 minutes.

- $\quad$ Additionally, MAS-assisted percutaneous gastrostomy tube placement can be done and this ensures proper location in the stomach and avoids injury to surrounding viscera.

\section{Laparoscopic Nissen fundoplication}

- $\quad$ Laparoscopic Nissen fundoplication enables excellent visualization of the esophageal hiatus.

- The morbidity of the surgical procedure, particularly complications, return of feeds, and hospital stay, is reduced with the use of a laparoscope.

- The laparoscopic technique is similar to the open technique and is typically performed with 5 ports, including the camera port. An angled $\left(30^{\circ}\right.$ or $\left.45^{\circ}\right)$ telescope is used.

- This procedure can also be combined with feeding tube gastrostomy.

- $\quad$ The major disadvantage with this procedure is the long learning curve associated with laparoscopic Nissen fundoplication.

\section{Laparoscopic Pyloromyotomy}

- $\quad$ Laparoscopic Pyloromyotomy is typically performed with 3 stab wounds without trocars. ${ }^{1}$ The average operating time is approximately 15 minutes.

- Most (>90\%) of the patients are discharged home within 24 hours.

- The cosmetic results are superior to the traditional right upper quadrant incisions.

\section{Laparoscopic Cholecystectomy}

- This is one of the most common laparoscopic procedures performed in adults.

- Laparoscopic cholecystectomy is traditionally performed with 4 ports, including the camera port. The size of these ports ranges from $2-10 \mathrm{~mm}$.

- Laparoscopic cholecystectomy has been shown to be safe, even in an infant ( $<19$ months). ${ }^{10}$

- Nowadays, many surgeons perform laparoscopic cholecystectomy using SILS (Single Incision Laparoscopic Surgery) technique. A solitary incision is made near the umbilical port. This serves both as telescopic port as well as working port.

\section{Laparoscopic Gastrectomy}

- Gastrectomies are now performed laparoscopically, both for benign as well as malignant lesions.

Indications of gastrectomy are:

- $\quad$ Perforation of the stomach wall

- Noncancerous polyps

- Stomach malignancies

- Bleeding gastric ulcer (Not amenable to medical treatment)

Both Billroth I and Billroth II gatrectomies can be performed laparoscopically. Generally $4-5$ ports are used and staplers are used for performing anastomosis. The advantages of laparoscopic gastrectomy are less postoperative pain, decreased hospitalization, and early return to routine activities. Using laparoscopic gastrectomy is restricted, 
however, only to patients with early-stage gastric cancers or those whose surgery is supposed to be palliation only.

\section{MAS Applications in the Midgut}

\section{Small bowel}

- Ajejunostomy tube can be placed laparoscopically.

- $\quad$ Small bowel can be resected if necessary, with intra- or extra-abdominal anastomosis, using staplers.

- Laparoscopy has been used to treat intestinal malrotation $^{12,11}$, small bowel atresia, adhesiolysis intussusception and Meckel's diverticulum. ${ }^{1}$

\section{Laparoscopic Appendectomy}

- Laparoscopic appendectomy was developed in the early 1980 s by the German gynecologists Semm and Schrieber. ${ }^{14,15}$

- In 1991, Valla et al reported the first series of pediatric laparoscopic appendectomies. ${ }^{15}$

- Laparoscopic appendectomy is being performed in increasing numbers throughout the Western world.

- Laparoscopic appendectomy is even more useful if diagnosis of appendicitis is equivocal, especially in girls.

- The laparoscopic approach allows better visualization of the rest of the abdominal cavity, allows better irrigation of the peritoneal cavity, and offers a lower wound infection rate than conventional appendctomy.

- $\quad$ Three ports (2-5 $\mathrm{mm}$ ) are typically used, although single-trocar appendectomy has also been described in the literature. ${ }^{16}$

\section{MAS Applications in the Hindgut}

\section{Colon}

- Laparoscopy has been used to treat diseases of the entire colon.

- Laparoscopic colectomy: Laparoscopic colectomy is technically demanding, and most surgeons have been reluctant to invest the time in mastering the procedure. ${ }^{17}$ Concerns had been raised over the safety of laparoscopic surgery for cancer after early reports of recurrence at the port site. ${ }^{18}$ But most of these fears have been seen to be unsubstantiated. ${ }^{19}$

- With the advent of stapling devices, the need for technically demanding intra corporeal suturing has been reduced. Besides stapling devices ensure a healthy anastomotic line, with complication rates being comparable to hand-sewn anastomosis.

- Hand assisted surgery: Development of hand assisted surgery has gained impetus from the efforts in laparoscopic colonic surgery. ${ }^{20}$ The surgeon's hand is introduced into the peritoneal cavity through a small incision. This allows direct palpation of the viscera and facilitates retraction and mobilization of the colon. Dissection and mobilization is carried out laparoscopically. The incision through which the hand is introduced can also be used to remove specimens or bring the ends of the colon to the surface for extracorporeal anastomosis.

- $\quad$ These operations are termed laparoscopically assisted because the anastomosis is done outside the body, with laparoscopy minimizing the size of wound necessary for mobilization and resection.

- $\quad$ Laparoscopy offers adequate visualization of the pelvic viscera and makes working in the deep pelvis easier and safer as compared to open surgery.

Laparoscopic pull-through for 'Hirschsprung's disease is done as follows:

- Classically, Hirschsprung's disease has been treated by staged procedures involving biopsy, colostomy, pullthrough, and colostomy takedown over a period of 6-12 months.

- It can be performed as a single-stage procedure in most patients, using MAS technique.

- In 1994, Curran, et al performed the first laparoscopic pull-through in a canine. ${ }^{21}$ It then was carried out in humans in 1994 by Smith, et al. ${ }^{22}$

- $\quad$ Laparoscopic pull-through has been shown to be safe in infants as young as 1 week and as small as $2.3 \mathrm{~kg}$.

- $\quad$ The procedure is carried out with 3-4 small (3.5-5 mm) ports in the mid abdomen. Sero-muscular biopsies are taken to check for mature ganglion cells in the proximal colon.

- The dissection is then begun transanally, and colon is removed to the level of biopsy-proven ganglionic cells, and if possible, a 2 to $5 \mathrm{~cm}$ margin is created.

- Anastomosis between the anus and neo-rectum is performed above the dentate line. ${ }^{4}$

- In one series as reported by Jona JZ, et al, the average operative time was 147 minutes and bowel function returned within 24 hours for more than $90 \%$ of patients. Patients stayed in the hospital for an average of 2 days postoperatively. ${ }^{24}$

\section{Imperforate anus}

- A perineal fistula is usually repaired in the newborn period without a colostomy.

- For other anorectal defects, most surgeons used to prefer the classical 3-step approach i.e., a diverting colostomy shortly after birth followed by the main repair at a later date and finally colostomy closure. ${ }^{25}$

- More recently, however, a trend to repair congenital malformations earlier in life has developed, and an increasing trend to perform primary procedures without a protective colostomy has developed. ${ }^{26}$

- The laparoscopic approach is more attractive because it allows the repair of the defect without laparotomy, without colostomy, and with minimal pain.

\section{MAS Applications in Hernia and other Surgeries}

\section{Laparoscopic Herniorrhaphy and Hernioplasty}

Inguinal hernia is common, and effective minimal 
access techniques have been developed. However, Laparoscopic techniques for hernia repair were not accepted readily. The reason for late acceptance for minimally invasive techniques for inguinal hernia was that the minimal access techniques were first advocated at the peak of a revolution in open surgical technique: the adoption of the open, tensionfree mesh (Lichtenstein) repair. ${ }^{27}$

The Lichenstein repair was shown to have recurrence rates tenfold lower than those of the Shouldice repair, which was then the standard. The surgical community embraced the new technique, ${ }^{27}$ with lot of enthusiasm. Thus the technical revolution of Laparoscopic hernia repair was met with skepticism.

Three techniques which gained acceptance were:

- TEP (Totally Extra Peritoneal) approach

- TAPP (Trans Abdominal Pre peritoneal) approach

- $\quad \operatorname{IPOM}($ Intra peritoneal On-lay Mesh)

The intraperitoneal on-lay mesh (IPOM) had an unacceptable rate of late complications and has since been abandoned - the remaining techniques are both safe and effective. $^{28}$

A further issue was that there was no superiority vis a vis open surgery in terms of patient recovery and long term recurrence rates did not differ significantly from those with the Lichtenstein repair.

Minimal access techniques, however, offered a clear technical benefit in patients with recurrent and bilateral hernias. Using MAS approach only one set of 3 incisions was sufficient to repair bilateral hernias whereas open surgery would require bilateral groin incisions.

\section{Laparoscopic Bariatric Surgeries}

Bariatric Surgeries are surgeries for weight loss in morbidly obese patients. Procedures performed can be:

- Restrictive

- Malabsorptive

- Both restrictive and malabsorptive

Bariatric surgeons worldwide have incorporated laparoscopy in their procedures. Laparoscopic sleeve gastrectomy is the gold standard technique and is most widely practised. Roux-en-Y Gastric by-pass and Duodenal switch are the other two commonly performed laparoscopic bariatric surgeries.

Laparoscopic bariatric surgeries require longer instruments, more sturdy operation tables, strict intraoperative monitoring of patients and a close liaison between the operating surgeon and an endocrinologist.

\section{Varicocele}

- Laparoscopic Palomo technique is usually performed with 1-3 trocars.

- In one study, the median operating time was approximately 30 minutes and the median hospital stay was 24 hours. Recurrence with the laparoscopic Palomo technique was low, but, the rate of postoperative hydrocele formation was significant (6.6\%). ${ }^{29}$

\section{Nonpalpable testes}

- MAS techniques must be used if the cryptorchid testis is not palpable in the inguinal canal.

- The first report of abdominal testes identified by laparoscopy was in $1976,{ }^{30}$ and since then, laparoscopy has become the standard for nonpalpable testes.

- Laparoscopy allows localization of intra-abdominal testes, identification of absence of testis and presence of canalicular testis. Once located, these intra-abdominal testes can be treated by MAS-assisted orchidopexy.

- The nonpalpable testes are usually found between the internal ring and the external iliac vessels. ${ }^{30}$

\section{Ovarian pathology}

- Laparoscopy has been used successfully to manage a wide variety of gynecologic problems, including tubal torsion and adnexal torsion.

- In teenaged girls with abdominal pain, diagnostic laparoscopy is a wonderful tool for arriving at a diagnosis. This is because of the multiple pathologies that can lead to lower abdominal pain in them.

- It can be performed easily with 2-3 ports and provides excellent operative view.

\section{MAS Applications in Solid Organs}

\section{Laparoscopic Splenectomy}

- $\quad$ The first MAS approach to splenectomy was successfully performed in 1990 in animals. ${ }^{31}$

- The first laparoscopic splenectomy was performed in Buffalo, New York. It has now become the criterion standard for removal of the spleen.

- Patients are usually placed in a supine position or in a $45^{\circ}$ right lateral decubitus position. Typically, 4-5 trocars of varying sizes $(5-12 \mathrm{~mm})$ are used.

- The spleen is placed in a bag, which is exteriorized and removed after breaking it with a finger or sponge stick.

- Patients do extremely well postoperatively, and most are able to return home within 48 hours. However, if a malignancy is suspected, open splenectomy is preferred.

- Partial splenectomy, splenopexy for wandering spleen, and splenic cyst excision all have been reported. There is a report of splenopexy being performed for a wander spleen in a 2-year-old girl. ${ }^{32}$

\section{Laparoscopic Nephrectomy}

- $\quad$ Laparoscopic nephrectomy was first described in 1991 in adults. ${ }^{33}$

- Transperitoneal or retroperitoneal approaches have been used.

- Ehrlich et al reported the first series of laparoscopic 
renal surgery in children. ${ }^{34}$ The retroperitoneal approach completely avoids the peritoneum, thereby decreasing the related complications. By using a retroperitoneal approach, the incidence of postoperative ileus decreases and the risk of postoperative adhesions are less. In patients who have had previous abdominal surgeries, the retroperitoneal approach is recommended.

- This approach can be used for renal biopsy, nephrectomy, heminephrectomy, nephro-ureterectomies, nephropexy, adrenalectomy, and pyeloplasty. ${ }^{35}$

- The retroperitoneum is dissected using balloon, saline, finger, or direct vision. Angled scopes are used as they provide a much better view of the limited space available in the retroperitoneum.

- $\quad$ Other urologic procedures have also been performed laparoscopically, including pyeloplasty, bladder reconstruction, and ureteral reimplantation.

\section{Laparoscopic Adrenalectomy}

- The MAS approach can be applied to adrenal tumors, particularly such as pheochromocytoma and incidentally found adrenal masses.

- The MAS approach can be transperitoneal or retroperitoneal.

- The magnified view obtained using a laparoscope makes the surgical anatomy and vascular supply more distinct than as seen using an open technique.

\section{MAS Applications in the Thorax}

\section{Thoracoscopy}

- In 1910, Jacobeus first introduced thoracoscopy for dissection of tuberculosis (TB) adhesions. ${ }^{36}$

- Patients are placed in a lateral position with the operative side up, as in the open technique. Three trocars are used in most cases for performing thoracoscopy.

Thoracoscopy is useful for the following:

- $\quad$ Assessment or resection of mediastinal or lung masses. ${ }^{37}$

- Tumor biopsies

- Closure of patent ductus arteriosus ${ }^{38}$

- Vascular rings ${ }^{39}$

- Diaphragm plication ${ }^{22}$

- $\quad$ Resection of subpleural blebs

- Pleurodesis

- Pericardial drainage

- Lung biopsies

- Drainage of empyema

\section{Conclusion and Future Directions}

Surgery has come a long way from the crude methods of the past to the refined techniques of the present. As accomplished a repertoire a surgeon might seem to have today in form of better instruments and excellent energy sources (including Ligasure and Harmonic scalpel), the scope for improvement is always there.

In the future remote handling technology will overcome the manipulative restriction in the current instruments. Robotic arms with multiple degrees of freedom let a surgeon achieve a degree of dexterity which is amiss in rigid laparoscopic instruments. The future is knocking on the door and banging hard, but as with all forms of technology, it depends upon how good the training is and how much the learning curve can be shortened.

Laparoscopic gallbladder surgery was first done 1987, but it became standard within five years. That day is not far off when surgeons will routinely be using minimal access devices to enter the body through natural orifices and ugly scars will be a memory in archives of text books only.

\section{References}

1. Georgeson KE, Owings E. Advances in minimally invasive surgery in children. AmJ Surg 2000;180:362-364.

2. Huizinga E. On esophagoscopy and swordswallowing. Ann Otol Rhinol Laryngol1969;78:32-39.

3. Cameron JL. Current Surgical Therapy. 6th ed. St. Louis, Mo: Mosby-Year Book. 1998:1159.

4. Tam PK. Laparoscopic surgery in children. Arch Dis Child 2000;240-243.

5. Monson JR, Darzi A, Carey PD, Guillou PJ. Thoracoscopic Heller's cardiomyotomy: a new approach for achalasia. Surg Laparosc Endosc 1994;4:6-8.

6. Darzi A, Henry MM, Guillou PJ, Shorvon P, Monson JR. Stapled laparoscopic rectopexy for rectal prolapse. Surg Endosc 1995;9:301-303.

7. Darzi A, Cheshire NJ, Somers SS, Super PA, Guillou PJ, Monson JR. Laparoscopic omental patch repair of perforated duodenal ulcer with an automated stapler. BrJ Surg 1993;80:1552.

8. Chen MK, Schropp KP, Lobe TE. Complications of minimal-access surgery in children.J Pediatr Surg 1996; 31:1161-65.

9. Rothenberg SS, Bealer JF, Chang JH. Primary laparoscopic placement of gastrostomy buttons for feeding tubes. A safer and simpler technique. Surg Endosc 1999; 13:995-997.

10. Rosser JC Jr, Boeckman CR, Andrews D. Laparoscopic cholecystectomy in an infant. Surg Laparosc Endosc 1992; 2:143-47.

11. Bax NM, van der Zee DC. Laparoscopic treatment of intestinal malrotation in children. Surg Endosc 1998; 12:1314-16.

12. Galatioto C, Angrisano C, Blois M, Goletti O, Buccianti P, Lorenzetti L, et al. Laparoscopic treatment of appendicocecal intussusception. Surg Laparosc Endosc Percutan Tech 1999; 9:362-64.

13. Teitelbaum DH, Polley TZ Jr, Obeid F. Laparoscopic 
diagnosis and excision of Meckel's diverticulum. $J$ Pediatr Surg 1994;29:495-97.

14. Schreiber JH. Laparoscopic appendectomy in pregnancy. Surg Endosc 1990;4:100-2.

15. Valla JS, Limonne B, Valla V, Montupet P, Daoud N, Grinda A et al. Laparoscopic appendectomy in children: report of 465 cases. Surg Laparosc Endosc 1991; 1:166-72.

16. Esposito C. One-trocar appendectomy in pediatric surgery. Surg Endosc 1998;12:177-78.

17. Darzi A, Hill AD, Henry MM, Guillou PJ, Monson JR. Laparoscopic assisted surgery of the colon. Operative technique. Endosc Surg Allied Technol 1993;1:13-15.

18. Nduka CC, Monson JR, Menzies-Gow N, Darzi A. Abdominal wall metastases following laparoscopy. $\mathrm{Br} J$ Surg 1994;81:648-52.

19. Parray FQ. Minimal access maximal success; A myth or a reality(Invited Editorial). International Journal of Surgery 2012;10:178-81.

20. Scott HJ, Darzi A. Tactile feedback in laparoscopic colonic surgery. BrJ Surg 1997;84:1005.

21. Curran TJ, Raffensperger JG. The feasibility of laparoscopic swenson pull-through. J Pediatr Surg 1994; 29:1273-75.

22. Smith BM, Steiner RB, Lobe TE. Laparoscopic Duhamel pullthrough procedure for Hirschsprung's disease in childhood.J Laparoendosc Surg 1994;4:273-76.

23. Rothenberg SS, Chang JH. Laparoscopic pull-through procedures using the harmonic scalpel in infants and children with Hirschsprung's disease. J Pediatr Surg 1997;32:894-96.

24. Jona JZ, Cohen RD, Georgeson KE, Rothenberg SS. Laparoscopic pull-through procedure for Hirschsprung's disease. Semin Pediatr Surg 1998;7:228-31.

25. Pena A, Hong A. Advances in the management of anorectal malformations. Am J Surg 2000;180:370-76.

26. Lichtenstein IL, Shulman AG, Amid PK, Montllor MM. The tension-free hernioplasty. Am J Surg 1989; 157:188-93.

27. Lichtenstein IL, Shulman AG, Amid PK. The cause, prevention, and treatment of recurrent groin hernia. Surg Clin North Am 1993;73:529-44.
28. Cocks JR. Laparoscopic inguinal hernioplasty: a comparison between transperitoneal and extraperitoneal techniques. Aust NZJ Surg 1998; 68: 506-9.

29. Esposito C, Monguzzi G, Gonzalez-Sabin MA, Rubino R, Montinaro L, Papparella A, et al. Results and complications of laparoscopic surgery for pediatric varicocele.J Pediatr Surg 2001;36:767-69.

30. Castilho LN. Laparoscopy for the nonpalpable testis: how to interpret the endoscopic findings. J Urol 1990; 144:1215-18.

31. Sackier JM, Berci G. Diagnostic and interventional laparoscopy for the general surgeon. Contemp Surg 1990; 37:15-26.

32. Hirose R, Kitano S, Bando T, Ueda Y, Sato K, Yoshida T et al. Laparoscopic splenopexy for pediatric wandering spleen.J Pediatr Surg 1998; 33:1571-73.

33. Clayman RV, Kavoussi LR, Soper NJ, Dierks SM, Meretyk S, Darcy MD, et al. Laparoscopic nephrectomy: initial case report.J Urol 1991; 146:278-82.

34. Ehrlich RM, Gershman A, Fuchs G. Laparoscopic renal surgery in children.J Urol 1994;151:735-39.

35. Rassweiler JJ, Seemann O, Frede T, Henkel TO, Alken P. Retroperitoneoscopy: experience with 200 cases. $J$ Urol 1998;160:1265-69.

36. Rodgers BM, Talbert JL. Thoracoscopy for diagnosis of intrathoracic lesions in children. J Pediatr Surg 1976; 11:703-8.

37. Michel JL, Revillon Y, Montupet P, Sauvat F, Sarnacki $\mathrm{S}$, Sayegh N, et al. Thoracoscopic treatment of mediastinal cysts in children. J Pediatr Surg 1998;33: 1745-48.

38. Laborde F, Folliguet T, Batisse A, Dibie A, Da-Cruz E Carbognani D, et al. Video-assisted thoracoscopic surgical interruption: the technique of choice for patent ductus arteriosus. Routine experience in 230 pediatric cases. J Thorac Cardiovasc Surg 1995;110:1681-4; discussion 1684-1685.

39. Burke RP, Michielon G, Wernovsky G. Video-assisted cardioscopy in congenital heart operations. Ann Thorac Surg 1994; 58:864-68. 